\title{
European Wood-Pastures in Transition - A Social-Ecological Approach
}

Tibor Hartel and Tobias Plieninger (eds.). 2014. ISBN 978-0-415-86989-8 Earthscan from Routledge/Taylor \& Francis Group, London and New York. 303 pages (hardcover). \$CA 161.88

n terms of European landscapes, wood-pastures constitute a prominent place. Yet this prominence was not matched by the attention accorded by scholars. This new volume, edited by Tibor Hartel and Tobias Plieninger, and with contributions from 28 other authors, has filled an important gap.

Divided into six parts, the book begins with three chapters in Part I to provide an overview of the European wood-pastures in terms of their social and ecological dimensions and high value as landscapes. Part II describes the origins and history of medieval wood-pastures, the recent dynamics of evergreen oak wood-pastures in southwestern Iberia, and the ecological patterns and processes at various spatiotemporal scales in the Swiss Jura Mountains. Part III focuses on the biological diversity and ecological structures of wood-pastures, whereas Part IV dwells upon the social-cultural values of wood-pasture systems. Part V is concerned with governance institutions, citing three case studies on management mechanisms and practices in Romania, Germany and the UK. The book ends with two chapters on the impact of Europe's contemporary agricultural policy on wood-pastures and future directions for conserving European wood-pastures.

Undoubtedly, wood-pastures represent a unique European cultural identity and have exceptional ecological values. For centuries, wood-pastures have persisted as a result of a balance between divergent ecological processes and locally driven socioeconomic needs. In recent decades, due to rapid global change, interactions between socioeconomic forces and ecological processes have been strongly influenced by growing tides of commodity production and urbanization. Hence, woodpastures are in decline all over Europe. This book offers a critical survey of broad societal changes and their effects on wood-pastures. The authors seek to convey a message that fundamental changes in societal values have eroded the traditional wood-pasture systems. In particular, the pursuit of economic efficiency and intensification in landuse practices has pushed wood-pastures to their ecological limit. As treed landscapes, wood-pastures belong to the oldest land-use types in Europe. A loud voice arising from the volume appeals for greater attention to the imperative of safeguarding the integrity of wood-pastures. Given the diverse types of woodpastures and multifaceted threats, the authors call for adapting management approaches to local situations.

This volume is a valuable read for natural resource professionals including foresters, livestock specialists, economists, and policy analysts. In particular, university students will benefit from the approach that the editors have employed in tackling a broad topical area that involves multiple disciplines. Evidently, efforts in combining social and ecological perspectives prove to be fruitful in generating an enhanced understanding of the underlying mechanisms that led to the decline of wood-

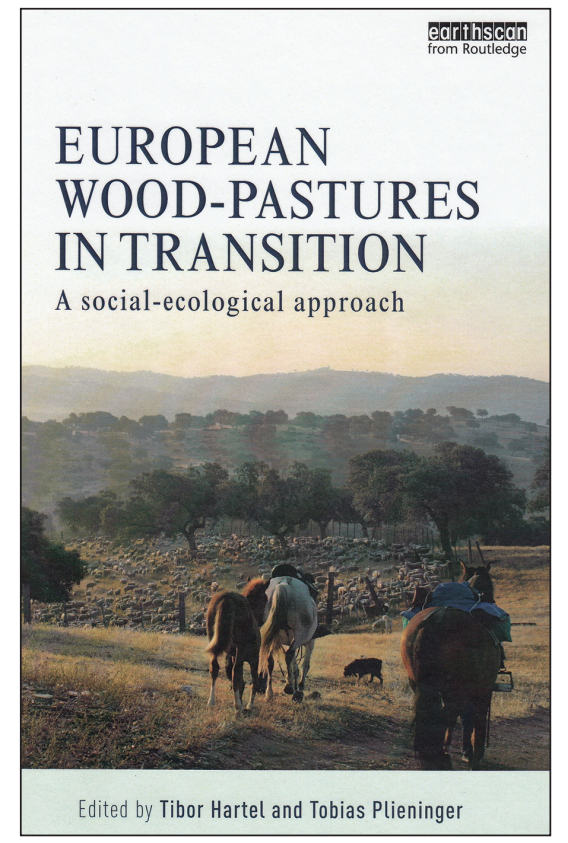

pastures in Europe. Recognizing the tremendous ecological, cultural and economic values of wood-pastures is a first step in the successful conservation of these landscapes down the road.

Reviewed by Dr. Sen Wang
Atlantic Forestry Centre
Fredericton, Canada 